\title{
Mercado de trabalho e processos regulatórios - a Enfermagem no Brasil
}

\author{
Labor market and regulatory processes - Nursing in Brazil
}

Maria Helena Machado (http://orcid.org/0000-0002-5209-2424) ${ }^{1}$

Isabella Koster (http://orcid.org/0000-0001-6061-2824) ${ }^{2}$

Wilson Aguiar Filho (http://orcid.org/0000-0003-2732-8578) ${ }^{2}$

Mônica Carvalho de Mesquita Werner Wermelinger (http://orcid.org/0000-0001-5861-5479) ${ }^{1}$

Neyson Pinheiro Freire (http://orcid.org/0000-0002-9038-9974) ${ }^{3}$

Everson Justino Pereira (http://orcid.org/0000-0002-4389-306X) ${ }^{2}$

${ }^{1}$ Escola Nacional de Saúde Pública Sérgio Arouca,

Fiocruz. R. Leopoldo Bulhões 1480, Manguinhos. 21041-210 Rio de Janeiro RJ Brasil.machado@ensp. fiocruz.br

${ }^{2}$ Núcleo de Estudos e Pesquisas em Recursos Humanos em Saúde

(Nerhus), Escola Nacional de Saúde Pública Sérgio Arouca, Fiocruz. Rio de Janeiro RJ Brasil.

${ }^{3}$ Conselho Federal de Enfermagem. Brasília DF Brasil.

\begin{abstract}
The present article analyzes the job market of nursing professionals, based on data obtained through the survey "Nursing Profile in Brazil" (Cofen - Fiocruz), showing that a significant portion of these workers, mostly nursing aides and technicians, live in increasingly precarious conditions of survival, with low wages, multi-employment and insecurity in the work environment, which prevents them from performing their work activities with dignity. It also analyzes the Nursing regulation process, having as reference the sociology of professions, from the creation of the Federal Nursing Council/Regional Nursing Councils System, in the 1970s, when the category started to have self-regulation autonomy, and currently, the profession shows a robust and highly regulatory legal milestone, considering the number of resolutions issued by Cofen, which have an impact on professional practice. The article points out that it is essential for the government to develop and improve job management and regulation policies, in order to contribute to overcome the problems faced by nursing professionals.
\end{abstract}

Key words Job Market, Professional Regulation, Nursing Profile in Brazil
Resumo O presente artigo faz uma análise do mercado de trabalho dos profissionais da Enfermagem, a partir dos dados obtidos através da Pesquisa Perfil da Enfermagem no Brasil (Cofen - Fiocruz), evidenciando que uma parcela significativa desses trabalhadores, a maioria auxiliares e técnicos de enfermagem, vivem em condições precárias de sobrevivência, com precarização, multiempregos e a insegurança no ambiente de trabatho cada vez mais frequentes, o que os impede de exercerem com dignidade suas atividades laborais. Analisa também o processo de regulação da Enfermagem, tendo como referencial a sociologia das profissões, a partir da criação do Sistema Conselho Federal/Conselhos Regionais de Enfermagem, na década de 1970, quando a categoria passa a ter autonomia da autorregulação, sendo que na atualidade, a profissão demonstra possuir um marco legal robusto e altamente regulador, considerando o quantitativo de resoluções emitidas pelo Cofen, que impactam sobre o exercício profissional. $O$ artigo aponta como sendo essencial que o Estado desenvolva e aprimore as politicas de gestão do trabalho e de regulação, de modo a contribuir para a superação dos problemas enfrentados pela Enfermagem.

Palavras-chave Mercado de trabalho, Regulação profissional, Perfil da Enfermagem no Brasil 


\section{Introdução}

A sociedade moderna tem se tornado crescentemente uma sociedade profissionalizada, fazendo com que boa parte das atividades humanas nela desenvolvidas busquem reconhecimento e status profissional, conquistando privilégios sociais e monopólio (quase sempre legais) de mercado de trabalho. A maioria de nossas ações e atividades está fundamentada ou referenciada em atos, critérios e normas profissionais. A sociedade contemporânea se caracteriza pela divisão do trabalho em diferentes atividades e áreas especializadas. A afirmação de Andrew Abbott ${ }^{1}$ de que as profissões dominam nosso mundo, nossos corpos, medem nossos lucros e salvam nossas almas, resume o quanto experimentamos o mito do profissionalismo.

O domínio e o monopólio do saber constituem o núcleo da autonomia das profissões e do seu prestígio social. Elas, de modo geral apelam, também, para o ideal de serviço na busca de crédito social e autonomia, que significa dizer que o interesse do paciente deve prevalecer sobre os interesses corporativos. Para Larson ${ }^{2}$, ideal de serviço e o código de ética, versões diferentes da mesma ideia de obrigação moral com a sociedade, são a principal resposta ideológica das profissões para a contradição entre conhecimento socialmente produzido, por um lado, e sua apropriação privada, sob a forma de expertise, do outro. Ambos são a justificativa e a garantia de que este conhecimento será devolvido à sociedade sob forma de serviços qualificados, que, no entanto, apresentam-se como elementos pré-capitalistas ou de antimercado, o que lhes confere uma conotação ideológica. São elementos que foram incorporados à organização das profissões por serem elementos que sustentam tanto o crédito social quanto a crença pública no caráter ético das profissões ${ }^{3}$.

Um fenômeno que tem se apresentado de forma crescente refere-se a um grande número de processos legais pelas mais diversas atividades técnicas solicitando seu reconhecimento enquanto profissão. E não se restringe à realidade brasileira, apresenta-se de maneira universal, num movimento de profissionalização crescente dessas ocupações. Tal demanda reflete a "necessidade social" de que os serviços de uma determinada área técnica ofereça à sociedade produtos diferenciados, especializados e de boa qualidade. Esses profissionais necessitam passar por um treinamento específico, serem constantemente avaliados por pares e terem normas e regras que os orientem sua praxis. Além disso, essa atividade necessita de regulamentação do Estado para garantir o monopólio e exclusividade do mercado de trabalho.

De maneira geral, há consenso entre os teóricos da área quanto a existência de dois atributos inquestionáveis, quais sejam, a existência de um corpo específico de conhecimentos e a orientação para um ideal de serviços.

Conceituando de uma forma mais clara, podemos dizer que profissão é uma ocupação cujas obrigações criam e utilizam de forma sistemática o conhecimento geral acumulado na solução de problemas postulados por um cliente, individual ou coletivo $^{4}$ (p. 18).

Segundo Freidson ${ }^{5}$ :

o projeto de mercado das profissões modernas olha para fora, para o mercado mais amplo, procurando estabelecer uma jurisdição segura na divisão social do trabalho, um abrigo no mercado de trabatho, ou seja, nos termos de Max Weber 'um cercado social', que exclua possíveis concorrentes externos à profissãa ${ }^{5}$ (p. 249).

Esse autor mostra ainda que as:

Fronteiras jurisdicionais razoavelmente firmes e estáveis que minimizam a concorrência de outras ocupações e as regras que controlam a competição entre os colegas criam condições de segurança econômica (ainda que não, necessariamente, de grande riqueza) suficientes para viabilizar um compromisso duradouro. (...) Permeiam tudo isso as linhas do projeto de mercado para obter uma proteção econômica coletiva contra a concorrência externa e do projeto de manutenção para preservar a solidariedade entre membros, protegendo a imagem pública da profissão e esquivando-se de tentativas de clientes, empregadores e outros de exercer controle sobre o trabalho de seus membros ${ }^{5}$ (p. 252).

Importante ressaltar que os mercados profissionalizados existentes atualmente no mundo emergiram ao meio das transformações advindas da Revolução Industrial e da consolidação do sistema capitalista. Tais fatos permitiram o surgimento de práticas e novas funções sociais tornando-se crescente a necessidade de profissionalismo em toda a sociedade industrializada ${ }^{2}$.

Por outro lado, tal como ocorreram com diversas profissões, na Enfermagem, os aspectos regulatórios requereram ações complexas envolvendo vários atores.

Para Moran e Wood ${ }^{6}$, estudiosos de regulação profissional, existem três modelos regulatórios. O primeiro refere-se a autorregulacão, ou seja, os próprios profissionais definem os mecanismos de entrada no mercado e de competência técni- 
ca. O segundo é a regulação com sanção estatal, caracterizada por instituições a cargo de formular e implementar mecanismos regulatórios com consentimento e apoio do Estado. Finalmente, a regulação direta do Estado, exercida por instituições públicas especializadas. Para esses autores o modelo de regulação é composto dos seguintes elementos: a) os mecanismos de entrada no mercado, incluindo licenciamento e certificação; b) o controle da competição profissional; c) a estrutura do mercado de trabalho e; d) o mecanismo de pagamento.

É esse o tema central deste artigo: o mercado de trabalho e o processo regulatório da profissão de Enfermagem à luz dos achados empíricos da Pesquisa Perfil da Enfermagem no Brasil - PPEB (2017), que faz um diagnóstico preciso e detalhado da situação dos enfermeiros, técnicos e auxiliares de enfermagem com quase dois milhões de trabalhadores inseridos no sistema de saúde do país. A pesquisa ouviu esses profissionais em mais de 50\% dos municípios, nas 27 unidades da Federação e nas 5 regiões do país. Portanto, temse hoje, a radiografia desta profissão permitindo uma compreensão mais precisa e fidedigna das realidades locais e nacional.

\section{Regulação profissional}

As primeiras medidas regulatórias da Enfermagem foram no campo da formação, com surgimento das escolas e cursos profissionalizantes. Contudo, mesmo após a instituição do Departamento Nacional de Saúde Pública, em 1923, a fiscalização das atividades de Enfermagem era subordinada à medicina ${ }^{7}$. Somente com a criação do Sistema Conselho Federal/Conselhos Regionais de Enfermagem, por meio da Lei $n^{\circ} 5.905 / 73^{8}$, a profissão passa a se autorregular, ganhando autonomia.

Essa "estrutura da burocracia racional-legal visa uma divisão de trabalho eficiente, formas de supervisão que possam efetivamente controlar e coordenar uma complexa variedade de tarefas especializadas e canais que tramitam livre e integralmente ordens, apelos, e informações para cima e para baixo na hierarquia. (...) O pessoal da organização é escolhido exclusivamente com base em sua competência para realizar um determinado tipo de trabalho, e é obrigado a realizar este trabalho sozinho. Seus direitos, deveres e responsabilidades são definidos com muita precisão, assim como sua autoridade sobre os outros e sua subordinação a eles"5 (p. 254).

Portanto: a regulação sobre o controle de entrada na profissão é realizada pelos Conselhos Regionais, em atenção às competências descritas nos incisos do artigo $15^{\circ}$ : I) deliberar sobre a inscrição no Conselho e seu cancelamento e VII) expedir carteira profissional indispensável ao exercício da profissão, a qual terá fé pública em todo território nacional e servirá de documento de identidade. A fiscalização do exercício profissional é realizada em alinhamento as diretrizes emitidas pelo Conselho Federal e compete aos Conselhos Regionais a sua execução conforme as competências relacionadas aos incisos do artigo 15०: II) disciplinar e fiscalizar o exercício profissional, observadas as diretrizes gerais do COFEN; IV) manter os registros dos profissionais com exercício na respectiva jurisdição; V) conhecer e decidir os assuntos atinentes à ética profissional, impondo as penalidades cabíveis ${ }^{9}$.

A fiscalização feita pelos Conselhos é a principal ação para assegurar a eficácia da Lei $\mathrm{n}^{\circ}$ $7.498 / 1986^{10}$, que regulamenta a atividade. No Brasil, a Enfermagem responde pela maior parte das atividades de cuidado em saúde totalizando um contingente de mais de 2,2 milhões de trabalhadores, representado pelo Enfermeiro, Técnico e Auxiliar de Enfermagem. Cabe ao Enfermeiro liderar o processo assistencial, atuando no gerenciamento da assistência de Enfermagem, fazendo a interrelação entre cuidar e administrar este cuidado.

A partir da lei do exercício profissional, é possível observar que há o reconhecimento de duas tipologias de Enfermeiro: o generalista e o obstetra, (Res. Cofen no 581/2018 ${ }^{11}$, que regulamenta as especialidades e $n^{\circ} 516 / 2016^{12}$, que estabelece as competências para atuação no campo da obstetrícia $)^{10}$. Outra medida oriunda da lei é a institucionalização de suas atividades, com a inclusão do planejamento e programação da assistência nas estruturas organizacionais, bem como a obrigatoriedade da direção do Serviço de Enfermagem e Supervisão como ações privativas do enfermeiro. Um elemento regulatório também importante é a consulta e prescrição da assistência de enfermagem. Neste sentido, o Cofen determina a instituição do Processo de Enfermagem e Sistematização da Assistência de Enfermagem (Res. Cofen no 358/2009 ${ }^{13}$ ), em todas as unidades de saúde.

Quanto à ampliação do escopo de práticas, a lei estabeleceu prerrogativas para os enfermeiros na prescrição de medicamentos (Res. Cofen no 195/1997), assegurando ademais a solicitação de exames estabelecidos nos Programas de Saúde Pública e rotinas institucionais ${ }^{14}$. Portanto, a re- 
gulamentação dessa prática atendia ao modelo de atenção pautado na atividade de alta relevância do enfermeiro no âmbito da saúde pública.

No caso do Brasil, outros entes também são responsáveis pela regulação da atividade da Enfermagem, com destaque para o Ministério da Saúde (MS), que institui as principais diretrizes clínicas para o Sistema Único de Saúde (SUS), por meio de protocolos. Contudo, David et al. ${ }^{15}$ mencionam que "o enfermeiro realiza o que é permitido no campo das negociações políticas entre as categorias, conforme as necessidades e contratualizações de interesses locais pela gestão e microgestão de poder". Desta forma, essas práticas estão em constante disputas jurisdicionais com as demais profissões de saúde. Nesse sentido, o Cofen afirma e delimita por resoluções e pareceres, questões jurisdicionais relacionadas à prática clínica. Vale destacar que essas resoluções corporificam para além da autorregulação, respostas aos ataques jurisdicionais das demais corporações da saúde. Essa capacidade responsiva do Cofen é analisada por Koster', que destaca o exponencial crescimento do número de resoluções após a promulgação do SUS em 1988, com a expansão de políticas de saúde do MS a partir da década de 1990 e prosseguindo até os dias atuais. (Gráfico 1).
Dentre o conjunto de resoluções, destacamse três: a) do Código de Ética Profissional; b) do funcionamento do sistema de fiscalização; c) da normatização da Responsabilidade Técnica, como capilarização da fiscalização do exercício profissional apontadas no Quadro 1.

Segundo Koster?:

Depois da primeira versão do Código de Ética ocorreram mais três outras reformulações. A primeira, em 1993, onde além da mudança do título para Código de Ética Profissional da Enfermagem, houve mudanças estruturais com exclusão do preâmbulo, aumento considerável dos artigos, inclusão de todos os profissionais da Enfermagem e ainda inclusão de um capitulo destinado as infrações e penalidades, tendo a Resolução Cofen $n^{\circ}$ 51/1979 sido revogada. A segunda, no ano 2000, com poucas mudanças, apenas retirou o artigo que tratava da propaganda de medicamentos, indicando ampliações no campo de atuação profissional da enfermagem. E a terceira, ocorreu em 2007, com grande expansão de sua estrutura para 132 artigos, divididos em sete capitulos, com quatro sessões cada um deles, que dizem respeito, respectivamente, as relações com a pessoa, a família e a comunidade; com os trabalhadores da Enfermagem; com as organizações da categoria profissional e por fim, com as organizações empregadoras.

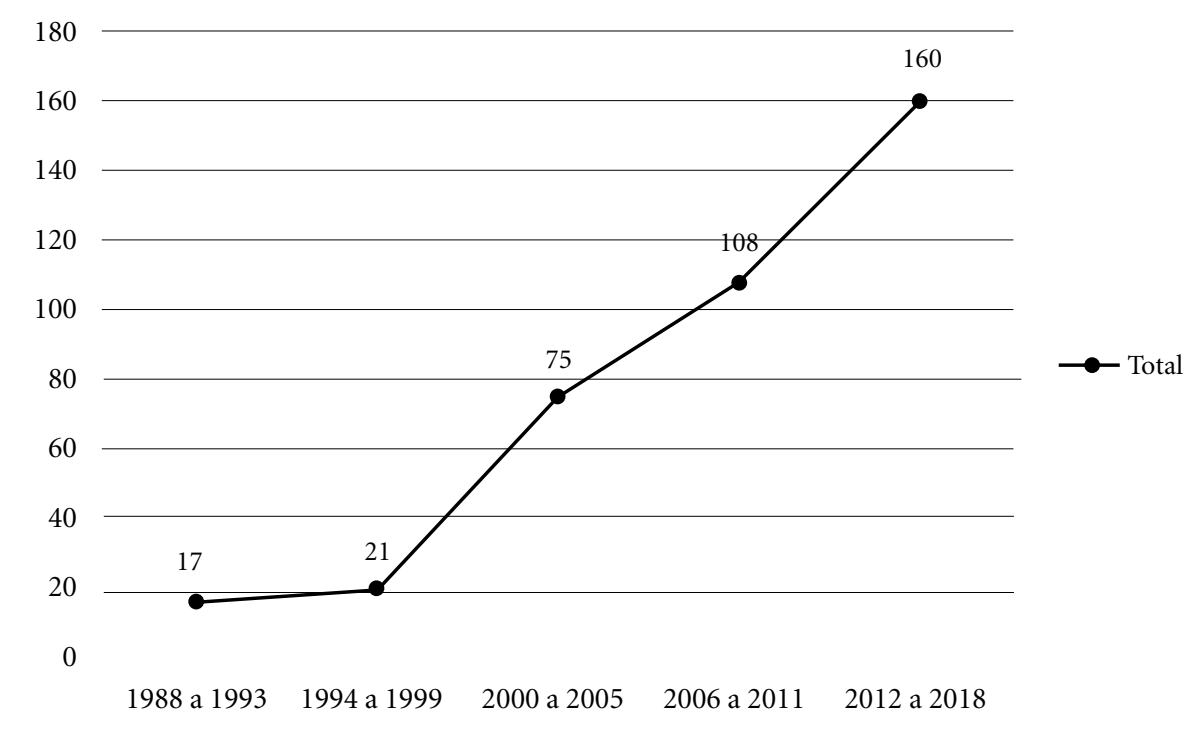

Gráfico 1. Distribuição do número de Resoluções por ano disponibilizadas no sítio do Conselho Federal de Enfermagem - Brasil. 
Quadro 1. Resoluções sobre regulação profissional da Enfermagem - Brasil.

\begin{tabular}{|l|l|l|}
\hline \multicolumn{1}{|c|}{ Resolução } & \multicolumn{1}{|c|}{ Normatização } & \multicolumn{1}{c|}{ Relevância } \\
\hline $\begin{array}{l}\text { Res. Cofen } \mathrm{n}^{\circ} \\
564 / 2017^{16}\end{array}$ & Código de Ética Profissional & $\begin{array}{l}\text { Instrumento crucial para o controle e fiscalização do } \\
\text { exercício profissional, que prevê os direitos, deveres, } \\
\text { proibições, infrações e penalidades. } \\
\text { Esta versão foi reelaborada com ampla discussão nos } \\
\text { Conselhos Regionais e consulta pública. }\end{array}$ \\
\hline $\begin{array}{l}\text { Res. Cofen no } \\
374 / 2011^{17}\end{array}$ & $\begin{array}{l}\text { Normatiza o funcionamento } \\
\text { do Sistema de Fiscalização } \\
\text { do Exercício profissional } \\
\text { da Enfermagem e dá outras } \\
\text { providências. }\end{array}$ & $\begin{array}{l}\text { Tem como base uma concepção de processo educativo, de } \\
\text { estímulo aos valores éticos e de valorização do processo } \\
\text { de trabalho em Enfermagem. Balizamento das ações de } \\
\text { fiscalização. Padronizaçães de condutas administrativas e } \\
\text { jurídicas. Revisão permanente dos métodos e ferramentas } \\
\text { de trabalho e das normas frente as mudanças tecnológicas } \\
\text { e inserção de novas práticas. Normatiza o modelo para } \\
\text { seleção e treinamento dos profissionais fiscais. }\end{array}$ \\
\hline $\begin{array}{l}\text { Res. Cofen no } \\
0509 / 2016^{18}\end{array}$ & $\begin{array}{l}\text { Atualiza a norma técnica para } \\
\text { Anotação de Responsabilidade } \\
\text { Técnica pelo Serviço de } \\
\text { Enfermagem e define as } \\
\text { atribuições do enfermeiro } \\
\text { Responsável Técnico - RT }\end{array}$ & $\begin{array}{l}\text { Poder de fiscalização concedido aos RTs para atuarem } \\
\text { como elo de ligação entre o serviço de Enfermagem } \\
\text { da instituição e o Sistema Cofen/Conselhos Regionais, } \\
\text { capilarizando a autorregulação. }\end{array}$ \\
\hline
\end{tabular}

Fonte: Elaboração própria a partir da análise das Res. do Cofen no 564, 374 e $509^{16-18}$.

$\mathrm{Na}$ análise de Koster ${ }^{9}$, o texto do atual Código de Ética, instituído pela Res. Cofen no 564/2017 ${ }^{16}$ : considera em seu escopo um conjunto de documentos e legislações voltados para a defesa dos direitos humanos, individuais ou de grupos prioritários, conquistados, envolvendo a bioética, a pesquisa com seres humanos, a violência contra mulher, a criança, adolescente e idoso e os portadores de transtornos mentais. Desta forma, a Enfermagem atualiza um de seus instrumentos de autorregulação, estabelecendo seus padrões de conduta e relacionamento entre seus pares, seus concorrentes e a sua clientela9.

Quanto ao fenômeno da especialização na Enfermagem, a análise aponta para questões referentes à regulação do exercício profissional e ao mercado de trabalho. Algumas, envolvendo as políticas públicas e modelos de atenção à saúde, tais como: Saúde Coletiva e áreas hospitalares. Outras atendem às exigências de áreas já regulamentadas, como a saúde do trabalhador e serviços de hemodiálise.

Fruto da evolução tecnológica, a Enfermagem se especializou em áreas de atuação. A primeira resolução sobre o tema é de 1998, regulamentando 8 especialidades. Em 2001, passa para 37; em 2004 evolui para 42, chegando a 60 especialidades no ano de 2018, o que representa aumento de 750\% (Figura 1), como aponta Koster 9.
Por outro lado, os dados da PPEB (2017) apontam que:

Apesar de 70\% dos enfermeiros terem realizado algum curso de Especialização, isto não se reflete quando a pergunta diz respeito a possuir ou não Título de Especialista. Neste caso, 51\% declaram possuir um título, o que torna possível inferir que parte significativa dos cursos oferecidos e realizados pelos enfermeiros não é reconhecido pela categorial mercado de trabalho, não conferindo a eles o status de especialista ${ }^{19}$ (p. 21).

Os autores analisam também que essa "especialização" da atividade reflete algo novo no mercado de trabalho da enfermagem, uma vez que "dos 211 mil enfermeiros que informaram possuir título de especialista, $47 \%$ obtiveram o título há 5 anos ou menos. Somando-se a faixa de 6-10 anos, o percentual eleva-se para $65,7 \%{ }^{19}$. Da mesma forma e acompanhando o mesmo processo, registra-se 18 especialidades para o técnico de Enfermagem, contida na Res. Cofen $n^{\circ}$ $609 / 2019^{20}$.

Quanto a regulamentação da prática assistencial, o Cofen tem emitido uma série de normas que respondem as necessidades e aos enfrentamentos do cotidiano da categoria. Desacatam-se o caso da autonomia para a inserção do Cateter Intervenoso Periférico (PIC); a realização de sutura/episiorrafia pelo enfermeiro obstetra; a co- 
Figura 1. Distribuição do número de especializações reconhecidas pelo Conselho Federal de Enfermagem segundo as Resoluções.

Fonte: Koster ${ }^{9}$.

leta de material para a colpocitologia oncótica como atividade privativa do enfermeiro; a autorização para realização da inserção de Dispositivo Intrauterino por enfermeiros; a delimitação das competências da equipe no tratamento de lesões, dando inclusive a autonomia para a abertura de consultórios de Enfermagem, entre outras, obtidas por meio de intervenção judicial do Conselho, como o reconhecimento da autonomia do enfermeiro na prática da acupuntura.

Como ilustração, recentemente, o Cofen normatizou a abertura de clínicas e consultórios de enfermagem, pelas Res. $n^{\text {o }} 568 / 2018^{21}$ e $n^{\circ}$ $606 / 2019^{22}$, conferindo o respaldo legal aos profissionais para a atuação autônoma; bem como resoluções sobre a regulamentação da Tabela de Honorários e a Responsabilidade Técnica do enfermeiro.

Observa, portanto, que a profissão estabelece um marco legal regulatório de impacto na sua praxis cotidiana observados não só pelo quantitativo de resoluções emitidas pelo Cofen, como pelo alcance e amplitude de áreas abrangidas.

\section{O Mercado de Trabalho}

O SUS, estabelecido na Constituição brasileira em 1988, é um dos maiores sistemas públicos do mundo e produziu, nesses 30 anos de existência, grandes transformações no sistema de saúde, representando

[...] uma nova forma de pensar, estruturar, desenvolver e produzir serviços e assistência em saúde, uma vez que os princípios da universalidade de acesso, da integralidade da atenção à saúde, da equidade, da participação da comunidade, da autonomia das pessoas e da descentralização constituem paradigmas do SUS. Algumas tendências são identificadas nesse processo [...]: 1) expansão da capacidade instalada; 2) municipalização dos empregos; 3) ambulatorização dos atendimentos; 4) maior qualificação da equipe; 5) feminização da força de trabalho; 6) flexibilidade dos vínculos, entre outras ${ }^{23}$ (p. 105).

No entanto, conforme assinala Machado et al. ${ }^{24}$ :

a forma como foi historicamente estruturado o modelo de assistência à saúde no Brasil reforçou 
as desigualdades regionais e a divisão de 'mercados de serviços' entre as esferas pública e privada. Se de um lado tem-se uma rede ambulatorial, predominantemente pública, constituída de centros de saúde e postos de assistência médica, destinados à prestação dos serviços em clínicas básicas, de outro, vemos que o setor privado possui a hegemonia no que concerne aos estabelecimentos com internação (hospitais), sendo responsável pela metade dos leitos existentes no País ${ }^{24}$ (p. 54).

Por outro lado, o Mercado de Trabalho (MT) do setor saúde experimentará uma forte expansão, o que irá impactar a dinâmica do setor. Machado e Ximenes Neto $^{25}$ analisam que:

Passados 30 anos desde a constituição do SUS, o Brasil tem a seguinte realidade sanitária (CNES, 2017): 200.049 estabelecimentos de saúde; 3.594.596 empregos de saúde. Em 2017, o setor público municipal contava com 1.649.074 empregos de saúde; o estadual com 463.720; e o federal com 96.491 empregos. A equipe de saúde passa a ser multiprofissional: enfermeiros, odontólogos, médicos, farmacêuticos, nutricionistas, fisioterapeutas, assistentes sociais, psicólogos, dentre outros; além de técnicos e auxiliares, em sua maioria. O setor saúde passa a contar com: 1.104 .340 empregos de nível superior; 889.630 técnicos e auxiliares; $e$ 317.056 de nivel elementar ${ }^{26}$. Atualmente, o Brasil conta com 453.428 médicos $^{27}, 484.530$ enfermeiros $^{28}, 300.000$ odontólogos ${ }^{29}$ e 203.600 farmacêuti$\cos ^{30} .{ }^{25}$ (p. 1976-1977).

A estruturação do MT é uma das bases do projeto profissional da Enfermagem. Ao longo das últimas décadas se constituiu um sólido mercado de serviços complexos e com credibilidade social.

Do ponto de vista demográfico, destacam-se o crescimento e o envelhecimento da população como explicativos dessa demanda. Do ponto de vista socioeconômico, a recuperação do mercado de trabalho e a ascensão social de parte significativa da população que estimularam o consumo dos planos de assistência médica, gerando fortes pressões para a produção de bens, serviços e tecnologias de saúde mais diversificados e qualificados. Já do ponto de vista político, destaca-se a própria consolidação do SUS e o avanço das políticas públicas da área, sobretudo da Estratégia Saúde da Família (ESF), principal responsável por descentralizar e expandir o mercado de trabalho da enfermagem e mudar o foco da assistência hospitalar para ambulatorial, domiciliar e comunitária. ${ }^{24}$ (p. 55-56).

Segundo dados da $\mathrm{PPEB}^{31}$, existia um contingente de 1.804 .535 profissionais, sendo 414.712 enfermeiros e 1.389.823 técnicos e auxiliares de Enfermagem. Já em 2019, o quantitativo atinge
2.169.402 profissionais, sendo 527.842 enfermeiros e 1.641 .560 profissionais de nível médio, dos quais 1.230 .182 são técnicos e 411.378 auxiliares de enfermagem ${ }^{32}$.

A Tabela 1 evidencia dados do MT da Enfermagem no qual os setores público e privado (subsetores com e sem fins lucrativos - filantrópico) são os grandes empregadores, sendo o público responsável por 55,6\% dos empregos e o privado $44,4 \%$ do total.

\section{Setor público}

Este setor tem dimensões continentais, composto por mais de 75 mil estabelecimentos de saúde, incorporando mais de 1 milhão de trabalhadores de Enfermagem, o que equivale a mais da metade da empregabilidade da categoria, seja na esfera municipal, estadual ou federal (Tabela 1).

Sua inserção no trabalho tem uma tipologia diversificada de vínculos. Os estatutários, regidos pelo Regime Jurídico Único, somam a metade do contingente $(49,9 \%)$, os vínculos celetistas, $17,7 \%$, os prestadores de serviços, $8,5 \%$ e por tempo determinado, $8,4 \%$. As OSCIPs, OS e Cooperativas somam $15,6 \%$.

Quanto às modalidades de instituição que atuam no setor, registra-se que $68,7 \%$ da equipe atuam em Hospitais e em Unidades de Urgência/Emergência somando mais de 976 mil profissionais. As UBS e serviços de saúde similares concentram o segundo maior contingente com $18,4 \%$, ou seja, mais de 261 mil. As Unidades ambulatoriais e Policlínicas empregam 6,2\%, cerca de 88 mil. Já as SADTs aglutinam mais de 19 mil profissionais $(1,4 \%)$. E atividades de Ensino, Pesquisa e Gestão são desempenhadas por mais de 75 mil (em boa parte, enfermeiros), equivalendo a $5,3 \%$.

Por outro lado, o plantão é o regime de trabalho mais utilizado nesse setor, com $57,1 \%$ (mais de 593 mil) e o trabalho diário com $42,9 \%$, o que soma mais de 445 mil.

Quanto a jornada de trabalho nesse setor público, a maioria $(63,8 \%)$ trabalha entre $21-40$ horas semanais e $34 \%$, mais de 41 horas. Na condição de "subjornada de trabalho" (carga horária igual ou inferior a 20 horas semanais), tem-se $2,2 \%$, ou seja, quase 21 mil profissionais.

$\mathrm{Na}$ prática, a jornada de trabalho da Enfermagem não é regulamentada em lei, valendo a livre negociação. Em geral, o governo federal, a maioria dos estados e os grandes municípios adotam a jornada de 30 horas semanais, enquanto que o setor privado, 40-44 horas. 
Tabela 1. Equipe de Enfermagem segundo atuação nos setores público e privado - Brasil.

\begin{tabular}{|c|c|c|c|c|c|c|}
\hline \multirow{3}{*}{ Atuação } & \multirow{2}{*}{\multicolumn{2}{|c|}{ Setor Público }} & \multicolumn{4}{|c|}{$\begin{array}{c}\text { Setor Privado } \\
\end{array}$} \\
\hline & & & \multicolumn{2}{|c|}{ Com fins lucrativos } & \multicolumn{2}{|c|}{ Sem fins lucrativos } \\
\hline & V.Abs. & $\%$ & V.Abs. & $\%$ & V.Abs. & $\%$ \\
\hline No. de Profissionais & 1.063 .694 & 55,6 & 571.099 & 29,9 & 278.283 & 14,5 \\
\hline \multicolumn{7}{|l|}{ Vínculos } \\
\hline Estatutário & 562.300 & 49,9 & 0 & 0,0 & 0 & 0,0 \\
\hline Celetista & 198.914 & 17,7 & 298.735 & 56,1 & 152.838 & 61,3 \\
\hline Por tempo determinado & 94.087 & 8,4 & 23.747 & 4,5 & 9.776 & 3,9 \\
\hline Prestador de serviço & 95.425 & 8,5 & 162.411 & 30,5 & 75.688 & 30,3 \\
\hline Outros & 175.417 & 15,6 & 47.646 & 8,9 & 11.122 & 4,5 \\
\hline Total & 1.126 .142 & 100,0 & 532.539 & 100,0 & 249.424 & 100,0 \\
\hline \multicolumn{7}{|l|}{ Modalidades de Instituição } \\
\hline $\begin{array}{l}\text { Hospitais e Unidades de Urgência/ } \\
\text { Emergência }\end{array}$ & 976.242 & 68,7 & 533.566 & 70,1 & 259.812 & 73,6 \\
\hline Unidades Básicas de Saúde - UBS & 261.682 & 18,4 & 18.904 & 2,5 & 0 & 0,0 \\
\hline $\begin{array}{l}\text { Unidades Ambulatoriais/ } \\
\text { Policlínicas }\end{array}$ & 88.122 & 6,2 & 78.643 & 10,3 & 43.007 & 12,2 \\
\hline $\begin{array}{l}\text { Unidades de Apoio de Diagnose e } \\
\text { Terapia - SADT }\end{array}$ & 19.486 & 1,4 & 67.212 & 8,8 & 46.751 & 13,3 \\
\hline \multirow[t]{2}{*}{ Ensino, Pesquisa e Gestão } & 75.335 & 5,3 & 62.909 & 8,3 & 3.247 & 0,9 \\
\hline & 1.420 .867 & 100,0 & 761.234 & 100,0 & 352.817 & 100,0 \\
\hline \multicolumn{7}{|l|}{ Regime de Trabalho } \\
\hline Trabalho diário & 445.725 & 42,9 & 220.296 & 43,8 & 117.402 & 45,2 \\
\hline \multirow[t]{2}{*}{ Plantão } & 593.336 & 57,1 & 282.308 & 56,2 & 142.132 & 54,8 \\
\hline & 1.039 .061 & 100,0 & 502.604 & 100,0 & 259.534 & 100,0 \\
\hline \multicolumn{7}{|l|}{ Horas Semanais Trabalhadas } \\
\hline Até 20 horas & 20.916 & 2,2 & 21.883 & 4,6 & 6.817 & 3,0 \\
\hline $21-40$ horas & 607.561 & 63,8 & 240.271 & 50,0 & 120.591 & 52,6 \\
\hline \multirow[t]{2}{*}{ Acima de 41 horas } & 324.185 & 34,0 & 218.004 & 45,4 & 101.644 & 44,4 \\
\hline & 952.662 & 100,0 & 480.157 & 100,0 & 229.052 & 100,0 \\
\hline \multicolumn{7}{|l|}{ Renda Mensal } \\
\hline Até 2.000 reais & 479.532 & 55,7 & 308.507 & 69,4 & 156.613 & 73,0 \\
\hline $2.001-5.000$ reais & 339.421 & 39,4 & 125.839 & 28,3 & 55.414 & 25,8 \\
\hline \multirow[t]{2}{*}{ Mais de 5.001 reais } & 41.472 & 4,8 & 10.052 & 2,3 & 2.562 & 1,2 \\
\hline & 860.425 & 100,0 & 444.397 & 100,0 & 214.589 & 100,0 \\
\hline \multicolumn{7}{|c|}{ Acidente de Trabalho nos Últimos 12 meses } \\
\hline $\operatorname{Sim}$ & 114.293 & 11,0 & 55.362 & 10,8 & 29.368 & 10,9 \\
\hline \multirow[t]{2}{*}{ Não } & 923.889 & 89,0 & 458.929 & 89,2 & 239.839 & 89,1 \\
\hline & 1.038 .182 & 100,0 & 514.291 & 100,0 & 269.207 & 100,0 \\
\hline \multicolumn{7}{|l|}{ Licença Médica nos Últimos 12 meses } \\
\hline $\operatorname{Sim}$ & 230.647 & 22,5 & 87.892 & 17,2 & 37.046 & 13,9 \\
\hline \multirow[t]{2}{*}{ Não } & 795.316 & 77,5 & 421.949 & 82,8 & 229.073 & 86,1 \\
\hline & 1.025 .963 & 100,0 & 509.841 & 100,0 & 266.118 & 100,0 \\
\hline \multicolumn{7}{|l|}{ Desemprego nos Últimos 12 meses } \\
\hline Sim & & & & & 182.548 & 10,7 \\
\hline \multirow[t]{2}{*}{ Não } & & & & & 1.519 .893 & 89,3 \\
\hline & & & & & 1.702 .441 & 100,0 \\
\hline \multicolumn{7}{|l|}{ Dificuldade de arrumar emprego } \\
\hline $\operatorname{Sim}$ & & & & & 121.697 & 70,0 \\
\hline \multirow[t]{2}{*}{ Não } & & & & & 52.068 & 30,0 \\
\hline & & & & & 173.765 & 100,0 \\
\hline
\end{tabular}

Fonte: Adaptado do Quadro Resumo: Machado ${ }^{31}$. 
A distribuição dos rendimentos nesse setor aponta a seguinte configuração: 1) 55,7\% têm renda mensal de até 2.000 reais; 2) 39,4\% percebem salários entre 2.001-5.000 reais; 3 ) os que têm renda acima de 5.001 reais são apenas 4,8\% (em agosto/2019, 1 dólar $=3,96$ reais).

\section{O setor privado}

Esse setor é constituído por mais de $60 \mathrm{mil}$ estabelecimentos de saúde, com mais de 840 mil profissionais, o que corresponde a $44,4 \%$ do total do contingente (Tabela 1).

No que se refere aos tipos de vínculos, o privado com fins lucrativos possui mais de $571 \mathrm{mil}$ profissionais, ou seja, 29,9\% do total. Duas formas de contratação predominam: CLT com quase 299 mil, ou 56,1\% e os prestadores de serviço, com $30,5 \%$. Já o privado sem fins lucrativos agrega 278 mil profissionais, $14,5 \%$ do total, sendo $61,3 \%$, vínculos CLT e os prestadores de serviço, $30,3 \%$.

Quanto as modalidades de instituição que atuam, no privado com fins lucrativos, os Hospitais e Unidades de Urgência/Emergência concentram a maioria absoluta, ou seja, $70,1 \%$, o que equivale a mais de 533 mil profissionais. Os serviços ambulatoriais englobam 10,3\%; as SADTs $8,8 \%$; as UBS apenas 2,5\%; e nas atividades de Ensino, Pesquisa e Gestão, 8,3\% (a maioria absoluta exercida por enfermeiros). Por sua vez, no privado sem fins lucrativos, os Hospitais e Unidades de Urgência/Emergência também concentram a maioria, com 73,6\%, quase 260 mil. As SADTs englobam 13,3\%; as Unidades Ambulatoriais, $12,2 \%$ e nas atividades de Ensino, Pesquisa e Gestão, a participação é mínima, apenas 0,9\%. Não há registro de atividades de enfermagem em UBS.

O regime de trabalho mais comum no setor privado com fins lucrativos é o plantão, utilizado por $56,2 \%$ da equipe e trabalho diário responde por $43,8 \%$. Quanto a jornada de trabalho, metade do contingente (50\%) tem jornadas de 21 40 horas semanais e $45,4 \%$ trabalham mais de 41 horas. Por outro lado, 4,6\% atuam com carga horária igual ou inferior a 20 horas semanais, ou seja, mais de 21 mil profissionais, o que caracteriza a existência de "subjornada de trabalho".

Já no privado sem fins lucrativos, o plantão também é o regime de trabalho predominante, com $54,8 \%$; o trabalho diário, representa $45,2 \%$. Já mais da metade do contingente $(52,6 \%)$ tem jornadas de 21-40 horas semanais e 44,4\%, de mais de 41 horas. E 3\% da equipe declaram atu- ar com carga horária igual ou inferior a 20 horas semanais, o que caracteriza "subjornadas de trabalho" no setor.

A distribuição dos rendimentos no privado com fins lucrativos mostra que: 1) 69,4\% têm renda mensal de até 2.000 reais; 2) 28,3\% percebem salário entre 2.001-5.000 reais; 3 ) e os que têm renda acima de 5.001, apenas 2,3\%. Por sua vez, o privado sem fins lucrativos tem a pior distribuição de rendimentos, comparado com os demais considerando que: 1) $73 \%$ da equipe têm renda mensal de até 2.000 reais; 2) 25,8\% percebem salário entre 2.001-5.000 reais; 3 ) e os que com renda acima de 5.001 somam apenas $1,2 \%{ }^{33}$.

Tomando os dados da PPEB é possível afirmar que:

a condição da equipe de enfermagem brasileira frente ao mercado de trabalho, reflete uma categoria profissional ativa economicamente falando, o que representa 91,8\% do total dos trabalhadores. No entanto, esse contingente dá sinais de problemas de empregabilidade plena, quando se registra quase $5 \%$ de desemprego aberto e 1,9\% que declaram afastamento temporário da atividade profissional, o que corresponde a mais de 100 mil trabalhadores. Relevante registrar também que mais de 6 mil destes, ou seja, 0,4\% abandonaram, definitivamente, a profissão. ${ }^{31}$ (p. 325).

Ainda considerando informações da Tabela 1, observa-se que $10,7 \%$ da equipe de enfermagem experimentaram desemprego nos últimos 12 meses e $70 \%$ reportam dificuldades em arrumar novo emprego. Fato que chama atenção são as taxas de acidente de trabalho na equipe de $11 \%$ no setor público e 10,9\% (média) para o privado, o que equivale a mais de 199 mil trabalhadores acidentados no ambiente de trabalho de saúde. Por outro lado, ainda mais grave é o registro de $22,5 \%$ de licenças médicas na equipe de enfermagem que atuam na esfera pública e 15,6\% (média) no privado.

\section{Notas finais}

Profissões tradicionais, tais como, advogados, médicos, enfermeiros, engenheiros, sacerdotes, têm experimentado transformações nos aspectos técnico-científicos, bem como desenham um reordenamento político-ideológico do "ideal de serviço". Os interesses corporativos, cada vez mais, buscam atender as demandas econômicas e responder as necessidades tecnológicas. Pode-se dizer que essas profissões passam por um processo de mudanças radicais alterando sua essência, 
com rupturas na autopercepção e em seu projeto profissional.

Nestas últimas duas décadas, os profissionais de Enfermagem no Brasil têm experimentado mudanças importantes no mundo do trabalho. O mercado de trabalho tem se mostrado com sinais claros de assalariamento com vinculação do salário a diversas formas: por plantão, por hora trabalhada, contratos curtos e temporários, ausência de vinculação institucional, gerando precarização, multiempregos e a insegurança no ambiente de trabalho são cada vez mais frequentes. A discussão sobre trabalho decente tem se tornado um tema recorrente entre as entidades sindicais que representam os trabalhadores.

A Organização Internacional do Trabalho (OIT) elenca sete dimensões inter-relacionadas de precariedade, em contraposição ao trabalho decente, quais sejam: 1) insegurança do mercado de trabalho pela ausência de oportunidades de trabalho; 2) insegurança do trabalho gerada pela proteção inadequada em caso de demissão; 3) insegurança de emprego gerada pela ausência de delimitações da atividade ou até mesma de qualificação de trabalho; 4) insegurança de integridade física $e$ de saúde em razão das más condições das instalações e do ambiente de trabalho; 5) insegurança de renda, fruto da baixa remuneração e ausência de expectativa de melhorias salariais; 6) insegurança de representação quando o trabalhador não se sente protegido e representado por um sindicato. ${ }^{25}$ (p. 1977-1978).

Os avanços tecnológicos registrados nessas últimas décadas têm exigido da profissão de Enfermagem a obter mais prestígio, status e uma grande habilidade em demonstrar sua capacidade resolutiva junto aos problemas de saúde da população. No entanto, estes avanços também têm efeitos negativos, gerando concorrência, disputas jurisdicionais no campo da regulação profissional, colocando em risco conquistas e até mesmo, perda de espaço no mercado de trabalho.

O controle burocrático gerencial implantado nas organizações de saúde (públicas ou privadas) tem sido apontado como sendo um sinal de novos tempos das formas de regulação do trabalho em saúde, o que denota o desequilíbrio da regulação do Estado entre as profissões. É fato que o sistema de saúde brasileiro não tem respondido à estas novas exigências tanto por parte dos profissionais de saúde como dos usuários. Ambos se sentem insatisfeitos com resultados destes avanços e as formas como o estado tem respondido a isso.

Se por um lado, as tensões das profissões sobre o Estado para o alcance de sua autonomia e controle de mercado são reconhecidamente legítimas, por outro, o Estado deve buscar promover um equilíbrio entre estes, de forma a garantir os princípios e diretrizes constitucionais para a saúde e tecer políticas de saúde para os seus trabalhadores.

\section{Colaboradores}

MH Machado, I Koster, MCMW Wermelinger, W Aguiar Filho, NP Freire e EJ Pereira participaram da concepção e delineamento do estudo, redação e revisão do conteúdo intelectual até a versão final do manuscrito. 


\section{Referências}

1. Abbott A. The system of professions. An Essay on the division of expert labor. London, Chicago: The University of Chicago Press; 1988.

2. Larson MS. The rise of professionalism. A sociological analysis. Berkeley, Los Angeles, London: University of California Press; 1977.

3. Machado MH. Os médicos e sua prática profissional: as metamorfoses de uma profissão [tese]. Rio de Janeiro: IUPERJ; 1996.

4. Machado MH. Sociologia das profissões: uma contribuição ao debate teórico. In: Machado $\mathrm{MH}$, organizadora. Profissões de saúde: uma abordagem sociológica. Rio de Janeiro: Editora Fiocruz; 1995. p. 13-31.

5. Freidson E. Renascimento do profissionalismo. Trad. CM Paciornik. São Paulo: Ed. USP; 1998.

6. Moran M, Wood B. States, regulation and the medical profession. Buckingham: Open University Press; 1993.

7. Kletemberg DF, Siqueira MTD, Mantovani MF, Padilha MI, Amante LN, Anders JC. O Processo de Enfermagem e a Lei do Exercício Profissional. Rev Bras Enferm 2010; 63(1):26-32.

8. Brasil. Lei no 5.905 , de 12 julho de 1973. Dispõe sobre a criação dos Conselhos Federal e Regionais de Enfermagem e dá outras providências. Diário Oficial da União 1973; 13 jul.

9. Koster I. O exercício profissional da enfermagem no âmbito da atenção primária à saúde no Brasil [tese]. Rio de Janeiro: Ensp/Fiocruz; 2019.

10. Brasil. Presidência da República. Casa Civil. Subchefia para Assuntos Jurídicos. Lei no 7.498, de 25 de junho de 1986. Dispõe sobre a regulamentação do exercício da Enfermagem e dá outras providências. Diário Oficial da União 1986; 26 jun.

11. Conselho Federal de Enfermagem (COFEN). Resolução COFEN no 581, de 11 de julho de 2018. Atualiza no âmbito do Sistema Cofen/Conselhos Regionais de Enfermagem, os procedimentos para Registro de Títulos de Pós-Graduação Lato e Stricto Sensu concedido a Enfermeiros e aprova a lista das especialidades. Diário Oficial da União 2018; 18 jul.

12. Conselho Federal de Enfermagem (COFEN). Resolução COFEN no 516, de 23 de junho de 2016. Normatiza a atuação e a responsabilidade do Enfermeiro, Enfermeiro Obstetra e Obstetriz na assistência às gestantes, parturientes, puérperas e recém-nascidos nos Serviços de Obstetrícia, Centros de Parto Normal e/ ou Casas de Parto e outros locais onde ocorra essa assistência; estabelece critérios para registro de títulos de Enfermeiro Obstetra e Obstetriz no âmbito do Sistema Cofen/Conselhos Regionais de Enfermagem, e dá outras providências. Diário Oficial da União 2016; 27 jun

13. Conselho Federal de Enfermagem (COFEN). Resolução COFEN no 358, de 15 de outubro de 2009. Dispõe sobre a Sistematização da Assistência de Enfermagem e a implementação do Processo de Enfermagem em ambientes, públicos ou privados, em que ocorre o cuidado profissional de Enfermagem, e dá outras providências. Diário Oficial da União 2009; 23 out.
14. Conselho Federal de Enfermagem (COFEN). Resolução COFEN no 195, de 18 de fevereiro de 1997. Autoriza a solicitação de exames de rotina e complementares pelos enfermeiros quando no exercício de suas atividades profissionais. Diário Oficial da União; 1997.

15. David HMSL, Acioli S, Seidl HM, Brandão PS. O enfermeiro na Atenção Básica: processo de trabalho, práticas de saúde e desafios contemporâneos. In: Mendonça MHM, Matta GC, Gondim R, Giovanella L, organizadores. Atenção Primária à Saúde no Brasil: conceitos, práticas e pesquisa. Rio de Janeiro: Fiocruz; 2018. p. 337-367.

16. Conselho Federal de Enfermagem (COFEN). Resolução COFEN no 564, de 6 de novembro de 2017. Aprova a reformulação do Código de Ética dos profissionais de enfermagem. Diário Oficial da União 2017; 6 dez.

17. Conselho Federal de Enfermagem (COFEN). Resolução COFEN no 374, de 23 de março de 2011. Normatiza o funcionamento do Sistema de Fiscalização do Exercício Profissional da Enfermagem e dá outras providências. Diário Oficial da União 2011; 25 mar.

18. Conselho Federal de Enfermagem (COFEN). Resolução COFEN no 509, de 15 de março de 2016. Atualiza a norma técnica para Anotação de Responsabilidade Técnica pelo Serviço de Enfermagem e define as atribuições do enfermeiro Responsável Técnico. Diário Oficial da União 2016; 16 mar.

19. Machado $\mathrm{MH}$, Wermelinger $\mathrm{M}$, Vieira $\mathrm{M}$, Oliveira E, Lemos W, Aguiar Filho W, Lacerda WF, Santos MR, Souza Junior PB, Justino E, Barbosa C. Aspectos gerais da formação da enfermagem: o perfil da formação dos enfermeiros, técnicos e auxiliares de enfermagem. Enferm Foco 2016; 7(n. esp.):15-34.

20. Conselho Federal de Enfermagem (COFEN). Resolução COFEN no 609, de $1^{\circ}$ de julho de 2019. Atualiza, no âmbito do Sistema Cofen/Conselhos Regionais de Enfermagem, os procedimentos para registro de especialização técnica de nível médio em Enfermagem concedida aos Técnicos de Enfermagem e aos Auxiliares de Enfermagem. Diário Oficial da União 2019; 3 jul.

21. Conselho Federal de Enfermagem (COFEN). Resolução COFEN no 568, de 9 de fevereiro de 2018. Aprova o Regulamento dos Consultórios de Enfermagem e Clínicas de Enfermagem. Diário Oficial da União 2018; 20 fev.

22. Conselho Federal de Enfermagem (COFEN). Resolução COFEN no 606, de 5 de abril de 2019. Inclui na Resolução Cofen $\mathrm{n}^{\circ}$ 568, de 9 de fevereiro de 2018, Anexos contendo modelo de Requerimento de $\mathrm{Ca}-$ dastro de Consultório e de Clínicas de Enfermagem e modelo de Registro de Consultório e de Clínicas de Enfermagem, no âmbito dos Conselhos Regionais de Enfermagem. Diário Oficial da União 2019; 9 abr.

23. Machado MH, Oliveira ES, Moysés, NMN. Tendências do mercado de trabalho em saúde no Brasil. In: Pierantoni C, Dal Poz MR, França T, organizadores. O trabalho em saúde: abordagens quantitativas e qualitativas. Rio de Janeiro: CEPESC, UERJ; 2011. p. 103116. 
24. Machado MH, Oliveira ES, Lemos WR, Lacerda WF, Justino E. Mercado de trabalho em enfermagem no âmbito do SUS: uma abordagem a partir da Pesquisa Perfil da Enfermagem no Brasil. Divulg Saude Debate 2016; 56:52-69.

25. Machado MH, Ximenes Neto FRG. Gestão, da Educação e do Trabalho em Saúde no SUS: trinta anos de avanços e desafios. Cien Saude Colet 2018; 23(6):19711980.

26. Instituto Brasileiro de Geografia e Estatística (IBGE). Pesquisa Nacional por Amostra de Domicílios: sintese de indicadores 2009. Rio de Janeiro: IBGE; 2010.

27. Conselho Federal de Medicina (CFM). Estatística: médicos em atividade no país [página na Internet]. [acessado 2018 Fev 11]. Disponível em: http://portal.cfm. org.br/index.php?option=com_estatistica

28. Conselho Federal de Enfermagem (COFEN). Enfermagem em números [página na Internet]. [acessado 2018 Fev 11]. Disponível em: http://www.cofen.gov. br/enfermagem-em-numeros

29. Conselho Federal de Odontologia (CFO). [página na Internet]. [acessado 2016 Dez 31]. Disponível em: http://transparenciacfo.org.br/

30. Conselho Federal de Farmácia (CFF). Número total registrado[página na Internet]. [acessado $2018 \mathrm{Fev}$ 11]. Disponível em: http://www.cff.org.br/pagina. php?id $=801 \&$ menu $=801 \&$ titulo $=$ Dados +2016

31. Machado MH, coordenadora. Pesquisa Perfil da Enfermagem no Brasil: Relatório Final. Rio de Janeiro: Nerhus-Daps-Ensp/Fiocruz; 2017.

32. Conselho Federal de Enfermagem (COFEN). Enfermagem em números[página na Internet]. [acessado 2019 Jul 15]. Disponível em: http://www.cofen.gov. br/enfermagem-em-numeros

33. Machado MH, Oliveira E, Lemos W, Lacerda WF, Aguiar Filho W, Wermelinger M, Vieira M, Santos MR, Souza Junior PB, Justino E, Barbosa C. Mercado de trabalho da Enfermagem: aspectos gerais. Enferm Foco 2016; 7(n. esp.):35-53.

Artigo apresentado em 07/04/2019

Aprovado em 20/08/2019

Versão final apresentada em 20/09/2019 